\title{
The HMGB1-RAGE/TLR-TNF- $\alpha$ signaling pathway may contribute to kidney injury induced by hypoxia
}

\author{
CHENG ZHANG, HUI DONG, FENGWEI CHEN, YUNXIA WANG, JING MA and GUANGFA WANG \\ Department of Respiratory and Critical Medicine, Peking University First Hospital, Beijing 100034, P.R. China
}

Received December 3, 2017; Accepted September 6, 2018

DOI: $10.3892 /$ etm.2018.6932

\begin{abstract}
The hypoxia-reoxygenation process of obstructive sleep apnea (OSA) may cause oxidative stress injury of the kidney, but the molecular mechanisms are not clear. The present study aimed to investigate whether high mobility group box 1 protein (HMGB1) and its subsequent inflammatory pathway served a role in kidney injury. Adult Sprague Dawley rats were used to establish hypoxia models: Continuous hypoxia, intermittent hypoxia and intermittent hypoxia with hypercapnia. Rat kidney tissues and peripheral blood samples were obtained. Histopathological and ultrastructural changes were observed by light and electron microscopy. Immunohistochemical (IHC) staining was used to detect the distribution of HMGB1. Reverse transcription-quantitative polymerase chain reaction (RT-qPCR) was used to detect the expression of HMGB1, receptor for advanced glycosylation end products (RAGE), toll-like receptor 4 (TLR4), nuclear factor kappa-light-chain-enhancer of active B cells $(\mathrm{NF}-\kappa \mathrm{B})$ p65 subunit, tumor necrosis factor- $\alpha$ (TNF- $\alpha)$, interleukin (IL)-6, NAD-dependent protein deacetylase sirtuin-1 (SIRT1), peroxisome proliferator-activated receptor (PPAR) mRNA in renal tissues. An ELISA was used to detect the expression of soluble TLR2, TLR4, PPAR- $\gamma$, TNF- $\alpha$, IL- 6 in peripheral blood. Hematoxylin \& eosin staining demonstrated that there was no serious injury to the kidneys due to hypoxia, with the exception of a certain degree of renal tubular epithelial cell vacuolation. By contrast, ultrastructural changes by electron microscopy were more significant in the hypoxia groups compared with the control, including foot process fusion in the glomerulus and degeneration of mitochondria in the proximal convoluted tubules. IHC also indicated increased expression of HMGB1 and nuclear translocation in the hypoxia groups. The results of the RT-qPCR demonstrated that hypoxia
\end{abstract}

Correspondence to: Dr Jing Ma or Dr Guangfa Wang, Department of Respiratory and Critical Medicine, Peking University First Hospital, 8 Xishiku Street, Xicheng, Beijing 100034, P.R. China E-mail: majjmail@163.com

E-mail: wangguangfa@hotmail.com

Key words: high mobility group box 1 protein, hypoxia, sleep apnea, renal injury, inflammation stimulation increased the expression of HMGB1, PPAR, RAGE and TNF- $\alpha$ mRNA, and decreased the expression of SIRT1 mRNA in kidney tissues $(\mathrm{P}<0.05)$. The results of the ELISA suggested that hypoxia stimulation increased the expression of soluble TLR4, TNF- $\alpha$ and IL- 6 in the peripheral blood, and decreased the expression of soluble TLR2 and PPAR- $\gamma$. In summary, hypoxia stimulation may cause early renal injury at the subcellular level and increase the expression and translocation of HMGB1. Hypoxia also upregulated the mRNA expression of the HMGB1-RAGE-TNF- $\alpha$ pathway in kidney tissue and increased the expression of soluble TLR4, TNF- $\alpha$ and IL- 6 in the peripheral blood. This suggested that the HMGB1-RAGE/TLR-TNF- $\alpha$ pathway may contribute to the molecular mechanisms of early renal injury induced by hypoxia. The pathway may contain potential markers for OSA-associated early renal injury and drug intervention targets in the future.

\section{Introduction}

Obstructive sleep apnea (OSA) is characterized by frequent nocturnal hypoxia, microarousal, oxidative stress and sympathetic activation, which is closely associated with hypertension, diabetes, chronic kidney disease (CKD) and other chronic diseases $(1,2)$. Previously, the association between sleep apnea and CKD has been widely discussed. The occurrence, development and prognosis of CKD and OSA are closely associated $(3,4)$. OSA, as a risk factor for $\mathrm{CKD}$, requires improved control to decrease the incidence of potential injuries that may occur. In addition to continuous positive airway pressure (CPAP) treatment, an organ protection strategy is particularly important in decreasing OSA-associated kidney injury. The method for overcoming this problem is to identify the core molecular mechanism in OSA-induced renal injury and investigate potential drug therapies. At present, evidence suggests that the primary mechanism of OSA-induced target organ injury is through immune inflammation (5).

Previously, high mobility group box 1 protein (HMGB1), as the most important representative damage-associated molecular pattern (DAMP) $(6,7)$, has attracted increasing attention. HMGB1 serves as a proinflammatory agent and may have a central role in inflammation $(8,9)$. HMGB1 is a highly conserved nuclear protein that is widely expressed in all types of mammalian cells, and is transferred from the nucleus to the 
cytoplasm and then released extracellularly upon receipt of inflammatory stimuli.

Extracellular HMGB1 may promote inflammation by binding to receptors on effector cell membranes, including macrophages and dendritic cells and leads to the release of inflammatory mediators, including interleukin (IL)-6 and tumor necrosis factor (TNF)- $\alpha$. In turn, the release of IL-6 and TNF- $\alpha$ leads to increased HMGB1 release, resulting a cascade amplification of inflammation $(8,9)$. The cell membrane receptors, in combination with HMGB1, are primarily receptors for advanced glycation end products (RAGE) (10) and Toll-like receptor (TLR) 4 and TLR2 (11). RAGE is a transmembrane protein of the immunoglobulin superfamily. It is widely expressed on a variety of cell surfaces, but the expression levels in normal tissues are low (12). When the ligands, including AGEs, HMGB1, S100 proteins are aggregated, the expression of RAGE increases $(2,13)$. TLRs are type I transmembrane proteins that activate the innate immune system (14). HMGB1 induces inflammation through binding to $\mathrm{RAGE}$ and TLR receptors through the nuclear factor kappa-light-chain-enhancer of active B cells $(N F-\kappa B)$ pathway.

The two inhibitors of this pathway are NAD-dependent protein deacetylase sirtuin-1 (SIRT1) and peroxisome proliferator-activated receptor (PPAR). SIRT1 is a member of the silent mating type information regulation 2 homolog (Sirtuin) family, and is a key anti-aging gene (15). The SIRT1 protein is an NAD+ dependent enzyme that deacetylates proteins, which contributes to cellular regulation (16). As an important deacetylase, SIRT1 may decrease the extent of HMGB1 acetylation and thereby decrease its activation and subsequent release into extracellular regions. In addition, PPAR is a member of the nuclear receptor transcription factor superfamily and includes three subtypes: PPAR $\alpha$; PPAR $\beta$; and PPAR $\gamma$, which are also types of ligand-inducible nuclear receptors (17). A previous study indicated that when combined with its inhibitory effect on the NF- $\kappa \mathrm{B}$ signaling pathway and therefore inhibit the transcription of HMGB1. The HMGB1-associated signaling pathways are summarized in Fig. 1.

In the present study, various intermittent hypoxia models were established to investigate the effects of hypoxia on the expression of HMGB1-RAGE/TLR-TNF- $\alpha$ signaling pathway in kidney tissues and peripheral blood, with the aim of identifying the molecular markers of OSA-induced renal injury and potential targets of drug intervention.

\section{Materials and methods}

Experimental animals. A total of 32 healthy adult male Sprague-Dawley (SD) rats weighing 280-320 g were provided by Beijing Weitong Lihua Experimental Animal Center (Beijing, China) and raised by Laboratory Animal Center of Peking University First Hospital (Beijing, China). The animals had ad libitum access to food and water, and were maintained at a temperature of $22 \pm 2^{\circ} \mathrm{C}$ and humidity of $40 \%$, in a 12-h light/dark cycle. The experimental animal procedures conformed with the relevant provisions of Regulations of the People's Republic of China on the Administration of Laboratory Animals. The present study was approved by the Animal Ethics Committee of Peking University First Hospital.
Reagents. Reverse transcription-quantitative polymerase chain reaction (RT-qPCR) reagents were purchased from Beijing TransGen Biotech Co., Ltd., (Beijing, China), which included Trans Zol Up Plus RNA kit (TransScript II All-in-One First-Strand cDNA Synthesis SuperMix for qPCR) and qPCR kit (TransStart Top Green qPCR kit SuperMix+Dye II).

The PCR primers were synthesized by Sangon Biotech Co., Ltd. (Shanghai, China) and primer sequences are summarized in Table I.

For the ELISA protocols: Rat TLR2 ELISA kit (cat. no., H299) and Rat PPAR ELISA kit (cat. no., H271; Nanjing Jiancheng Bioengineering Institute, Nanjing, China), TLR4 (cat. no., SEA753Ra; Cloud-Clone Corp., Katy, TX, USA), IL-6 (cat. no., R6000B) and TNF- $\alpha$ (cat. no., RTA00; both R\&D Systems, Inc., Minneapolis, MN, USA) were purchased.

For the immunohistochemistry protocols, the primary antibody was HMGB1 rabbit mAb (cat. no., 6893S; Cell Signaling Technology, Inc., Danvers, MA, USA) at a dilution of 1:400. The secondary antibody used was a horseradish peroxide (HRP)-conjugated goat anti-rabbit IgG (cat. no., Ab6721; Abcam, Cambridge, UK) at a dilution of 1:200.

\section{Establishment of hypoxia models and specimen collection} Hypoxia models. A hypoxia chamber was jointly developed with the Academy for Advanced Interdisciplinary Studies, Peking University (Beijing, China).

Continuous hypoxia $(\mathrm{CH})$. The rats were placed in the hypoxia chamber for $8 \mathrm{~h} /$ day for 2 weeks. The oxygen concentration in the hypoxia chamber was maintained at $10.0 \pm 0.5 \%(n=8)$.

Intermittent hypoxia $(\mathrm{IH})$. The rats were placed in the hypoxia chamber for $8 \mathrm{~h} /$ day for 2 weeks. The oxygen concentration in the hypoxia chamber was maintained at between $10-21 \%$ with a 2 min cycle time $\left(10 \% \mathrm{O}_{2}\right.$ for $1 \mathrm{~min}-21 \% \mathrm{O}_{2}$ for $1 \mathrm{~min}$; $\left.\mathrm{n}=8\right)$.

Intermittent hypoxia with hypercapnia $(\mathrm{IHH})$. The rats were placed in the hypoxia chamber for $8 \mathrm{~h}$ /day for 2 weeks. The oxygen and $\mathrm{CO}_{2}$ concentration in the hypoxia chamber was maintained with a 2 min circulation time $\left(10 \% \mathrm{O}_{2}+5 \% \mathrm{CO}_{2}\right.$ for $1 \mathrm{~min}$ then $21 \% \mathrm{O}_{2}+0-0.5 \% \mathrm{CO}_{2}$ for $1 \mathrm{~min}$; $\mathrm{n}=8$ ).

Control (C). SD rats were placed in the chamber with ad libitum access to food and water, breathing normal air for 8 h/day for 2 weeks $(n=8)$.

Specimen collection. On the day following the completion of the intervention, the rats were intraperitoneally anesthetized with $4 \mathrm{ml} / \mathrm{kg} 10 \%$ chloral hydrate $(0.4 \mathrm{~g} / \mathrm{kg})$. Then, blood samples were collected for a blood routine test and for collecting plasma following centrifugation ( $716 \mathrm{x} \mathrm{g} ; 10 \mathrm{~min}$; room temperature). Rats were sacrificed and the kidney tissues of the rats were collected and preserved in a refrigerator at $-80^{\circ} \mathrm{C}$, fixed in $4 \%$ paraformaldehyde at room temperature for $24-48 \mathrm{~h}$ or $2.5 \%$ glutaraldehyde at $4^{\circ} \mathrm{C}$ for 2-12 $\mathrm{h}$ for subsequent analysis.

\section{Specimen detection}

Hematoxylin and eosin (HE) and immunohistochemistry (IHC) staining sample preparation. Kidney tissues were immediately fixed in $4 \%$ paraformaldehyde at room temperature for 


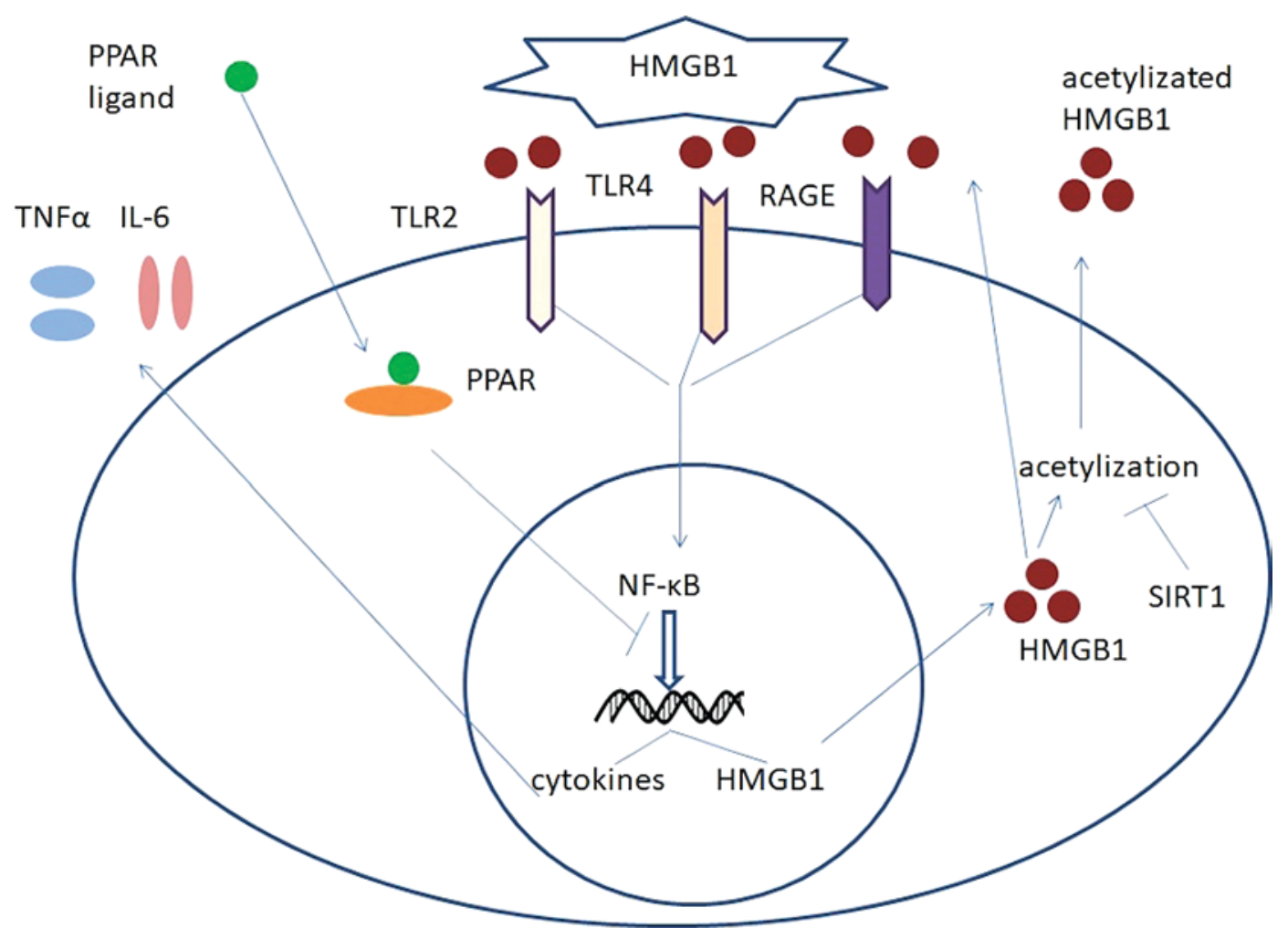

Figure 1. HMGB1-RAGE/TLR-TNF- $\alpha$ signaling pathway. HMGB1, high mobility group box 1 protein; RAGE, receptor for advanced glycosylation end products; TLR, toll-like receptor; TNF- $\alpha$, tumor necrosis factor; PPAR, peroxisome proliferator-activated receptor; IL, interleukin; SIRT1, NAD-dependent protein deacetylase sirtuin-1; $\rightarrow$, induce or product; -l, inhibit.

24-48 $\mathrm{h}$ and then dehydrated with an ethanol concentration gradient $(50,70,85,95$ and $100 \%)$ then cleared in xylene of room temperature and finally embedded in paraffin. The tissue blocks were sectioned at $5 \mu \mathrm{m}$ thickness, and then used for $\mathrm{HE}$ and IHC staining.

HE staining. All steps were performed at room temperature. Prior to staining, the sections were dewaxed in xylene $(100 \%$; $20 \mathrm{~min}$ ), rehydrated through decreasing concentrations of ethanol (100\% for $10 \mathrm{~min}$; and 95, 90, 80 and 70\% for $5 \mathrm{~min}$ each) and washed in PBS. Samples were incubated in hematoxylin solution for 8-15 min and wash with water 1-2 min. Samples were then placed in $1 \%$ hydrochloric acid in alcohol for differentiation for a $30 \mathrm{sec}$, followed by washing with water (30-60 min). Samples were immersed in $1 \%$ eosin solution for 2-5 min followed by washing with water. Following staining, sections were dehydrated through increasing concentrations of ethanol and xylene (ethanol, 95 and 100\% for $5 \mathrm{~min}$; xylene, 100\% $5 \mathrm{~min}$ ).

IHC. Hydrogen peroxide (3\%) was used for $10 \mathrm{~min}$ at room temperature for blocking of endogenous peroxides. Sections were blocked with $10 \%$ fetal bovine serum (FBS; ExCell Biology, Inc., Shanghai, China) at room temperature for $1 \mathrm{~h}$. Following the removal of FBS, sections were incubated with the HMGB1 primary antibody (rabbit; cat. no., 6893S; Cell Signaling Technology, Inc.) at 1:400 dilution at $4^{\circ} \mathrm{C}$ overnight. Incubation with the secondary antibody (goat anti-Rabbit IgG; 1:200; cat. no., Ab6721; Abcam) was performed at room temperature for $1 \mathrm{~h}$. Staining of HE and IHC were observed by light microscope (magnifications, x100, x200 and x400).
Transmission electron microscope observation. A small section (1-2 $\left.\mathrm{mm}^{3}\right)$ of kidney tissue was fixed in $2.5 \%$ glutaraldehyde $\left(4^{\circ} \mathrm{C} ; 2-12 \mathrm{~h}\right)$, post-fixed in $1 \%$ osmium tetroxide, dehydrated in serial acetone $(50,70,90$ and $100 \%)$, and embedded in Epon 812 resin $\left(37^{\circ} \mathrm{C}\right.$ for $6 \mathrm{~h} ; 60^{\circ} \mathrm{C}$ for $\left.48 \mathrm{~h}\right)$. The ultrathin sections (70-90 nm) were then stained using saturated uranyl acetate (15 min; room temperature) and standard lead citrate solution (A, $1.33 \mathrm{~g} \mathrm{~Pb}\left(\mathrm{NO}_{3}\right)_{2}$ and $1.76 \mathrm{~g} \mathrm{Na}_{3} \mathrm{C}_{6} \mathrm{H}_{5} \mathrm{O}_{7} \mathrm{x} 2 \mathrm{H}_{2} \mathrm{O}$ in $30 \mathrm{ml}$ water; $\mathrm{B}, 1 \mathrm{M} \mathrm{NaOH} ; 30 \mathrm{ml}$ A plus $8 \mathrm{ml} \mathrm{B}$ to $50 \mathrm{ml}$ with water; $15 \mathrm{~min}$; room temperature), then examined by a transmission electron microscope (magnifications, x8,000 and x15,000; JEM-1230; JEOL Ltd., Tokyo, Japan).

$R T-q P C R$. Total RNA was extracted from the kidney tissues using TRIZOL method. Total RNA quantification and purity were determined by ultraviolet spectrophotometry. cDNA was reverse transcribed by random primers using the Trans Script II All-in-One First-Strand cDNA Synthesis SuperMix for qPCR kit according to the protocol of the manufacturer. The reverse transcription cDNA products were stored at $-80^{\circ} \mathrm{C}$ for PCR amplification.

According to the instruction of the SYBR Green PCR kit, the following reagents were added to the PCR tube: $1 \mu \mathrm{lDNA}$ template, $0.4 \mu$ l forward primer $(10 \mu \mathrm{M}), 0.4 \mu \mathrm{l}$ reverse primer $(10 \mu \mathrm{M}), 10 \mu \mathrm{l} 2 \mathrm{X}$ TransStar Tip Green qPCR SuperMix,

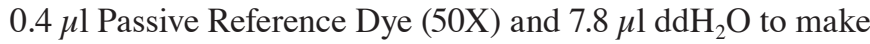
a $20 \mu \mathrm{l}$ total reaction system. The thermocycling conditions for the PCR were as follows: 40 cycles of $94^{\circ} \mathrm{C}$ for $30 \mathrm{sec} ; 94^{\circ} \mathrm{C}$ for $5 \mathrm{sec}$ and $60^{\circ} \mathrm{C}$ for $30 \mathrm{sec}$. The thermocycling conditions for the melting curve analysis were: $95^{\circ} \mathrm{C}$ for $15 \mathrm{sec}, 60^{\circ} \mathrm{C}$ for $60 \mathrm{sec}$, 
Table I. Quantitative polymerase chain reaction primer sequences of HMGB1, TLR4, NF- $\kappa$ B, RAGE, TNF- $\alpha$, IL-6, PPAR, SIRT1 and internal reference 28S.

\begin{tabular}{|c|c|}
\hline Gene & Sequence $\left(5^{\prime}-3^{\prime}\right)$ \\
\hline HMGB1-F & CTAGCCCTGTCCTGGTGGTATT \\
\hline HMGB1-R & CCAATTTACAACCCCCAGACTGT \\
\hline TLR4-F & TCAACCCCCTGAAGATCTTAAGAA \\
\hline TLR4-R & ATGCCTTGTCTTCAATTGTCTCAA \\
\hline $\begin{array}{l}\text { RELA } \\
(\mathrm{NF \kappa B3P65)-F}\end{array}$ & TGGCTTCTATGAGGCTGAACTCT \\
\hline $\begin{array}{l}\text { RELA } \\
(\mathrm{NF \kappa B3P65)-R}\end{array}$ & GGATCCCCAGGTTCTGGAA \\
\hline RAGE-F & AGGAAAGCCCTCCTGTCAACA \\
\hline RAGE-R & CACAGAGCCTGCAGCTTGTC \\
\hline TNF- $\alpha-F$ & CCACCACGCTCTTCTGTCTA \\
\hline TNF- $\alpha-R$ & ACTGATGAGAGGGAGCCCATT \\
\hline IL-6-F & TCTGGTCTTCTGGAGTTCCGT \\
\hline IL-6-R & GCATTGGAAGTTGGGGTAGGA \\
\hline $\operatorname{PPAR} \gamma-\mathrm{F}$ & TGACTTGGCCATATTTATAGCTGTCA \\
\hline PPAR $\gamma-R$ & GATGTCCTCGATGGGCTTCA \\
\hline Sirt1-F & GCTGGCCTAATAGACTTGCAAAG \\
\hline Sirt1-R & ATGTAACGATTTGGTGGTACAAACA \\
\hline $\begin{array}{l}28 \mathrm{~S} \text { ribosomal } \\
\text { RNA-F }\end{array}$ & TGCCATGGTAATCCTGCTCA \\
\hline $\begin{array}{l}28 \mathrm{~S} \text { ribosomal } \\
\text { RNA-R }\end{array}$ & CCTCAGCCAAGCACATACACC \\
\hline \multicolumn{2}{|c|}{$\begin{array}{l}\text { F, forward; R, reverse; HMGB } 1 \text {, high mobility group box } 1 \text { protein; } \\
\text { RAGE, receptor for advanced glycosylation end products; TLR, } \\
\text { toll-like receptor; TNF- } \alpha \text {, tumor necrosis factor } \alpha \text {; IL, interleukin; } \\
\text { NF- } \mathrm{B} \text {, nuclear factor kappa-light-chain-enhancer of active B cells; } \\
\text { RELA, nuclear factor NF- } \mathrm{B} \text { p } 65 \text { subunit; PPAR, peroxisome } \\
\text { proliferator-activated receptor; SIRT1, NAD-dependent protein } \\
\text { deacetylase sirtuin- } 1 \text {. }\end{array}$} \\
\hline
\end{tabular}

$95^{\circ} \mathrm{C}$ for $30 \mathrm{sec}$ and $60^{\circ} \mathrm{C}$ for $15 \mathrm{sec}$. The real time qPCR was completed using an ABI 7500 Realtime PCR system. The $28 \mathrm{~S}$ gene was used as the reference gene. The $2^{-\Delta \Delta \mathrm{Cq}}$ method (18) was used to analyze the data.

ELISA. These experiments were performed according to the protocols of the kit manufacturers. All reagents and working fluids were prepared and maintained at room temperature. The 96-well enzyme-labeled plates were prepared. The standard solution and peripheral blood samples were added, with two repeated wells for each sample. HRP was added, mixed and incubated. The plates were washed and dried. The color reagent was added to each well. Then, the termination fluid was added. The optical density value of each well was measured at $450 \mathrm{~nm}$. A standard curve was calculated and the concentration of each specimen was calculated.

Statistical analysis. SPSS 17 statistical software (SPSS, Inc., Chicago, IL, USA) was used for data processing. Continuous variables are presented as the mean \pm standard deviation.

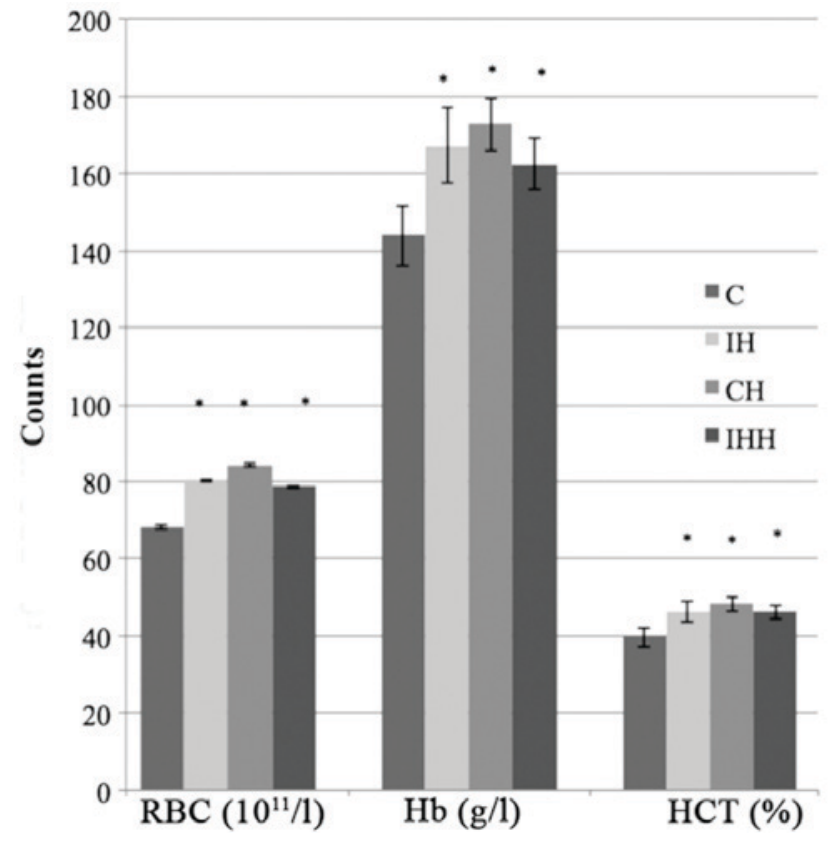

Figure 2. Red-cell count, hemoglobin and hematocrit levels of hypoxia and control groups. ${ }^{*} \mathrm{P}<0.05$ vs. controls. RBC, red blood cell count; $\mathrm{Hb}$, hemoglobin; HCT, hematocrit; C, control; IH, intermittent hypoxia; $\mathrm{CH}$, continuous hypoxia; IHH, intermittent hypoxia with hypercapnia.

Comparisons between the groups were evaluated by one-way analysis of variance followed by Least Significant Difference multiple comparison, or by the nonparametric Kruskal-Wallis test, according to the results of the homogeneity of variance test. $\mathrm{P}<0.05$ was considered to indicate a statistically significant difference.

\section{Results}

Routine blood testing. The red-cell count, hemoglobin and hematocrit levels of the three different models of hypoxia were significantly increased compared with those of control group $(\mathrm{P}<0.05$; Fig. 2), suggesting that successful hypoxia models were established.

Renal HE staining. Overall, kidney injury was not serious in any of the different hypoxia groups, as indicated by the HE staining. The HE staining demonstrated a certain degree of renal tubular epithelial cell vacuolation in the different types of hypoxia groups, as presented in Fig. 3 .

Ultrastructural observation. Transmission electron micrographs of rat kidney tissues were captured. Fusion of the foot process was visualized in the glomerulus. In the proximal convoluted tubules, additional secondary lysosomes and vacuoles were observed. Swelling and degeneration of mitochondria was identified in the tubules (Fig. 4).

HMGB1 immunohistochemical staining of renal tissues. HMGB1 immunohistochemical staining of renal tissues suggested that the HMGB1 protein was primarily expressed in the nucleus of the renal tubular epithelial cells in the control group. In the hypoxia groups, the expression of HMGB1, in particular the extracellular expression was increased, 

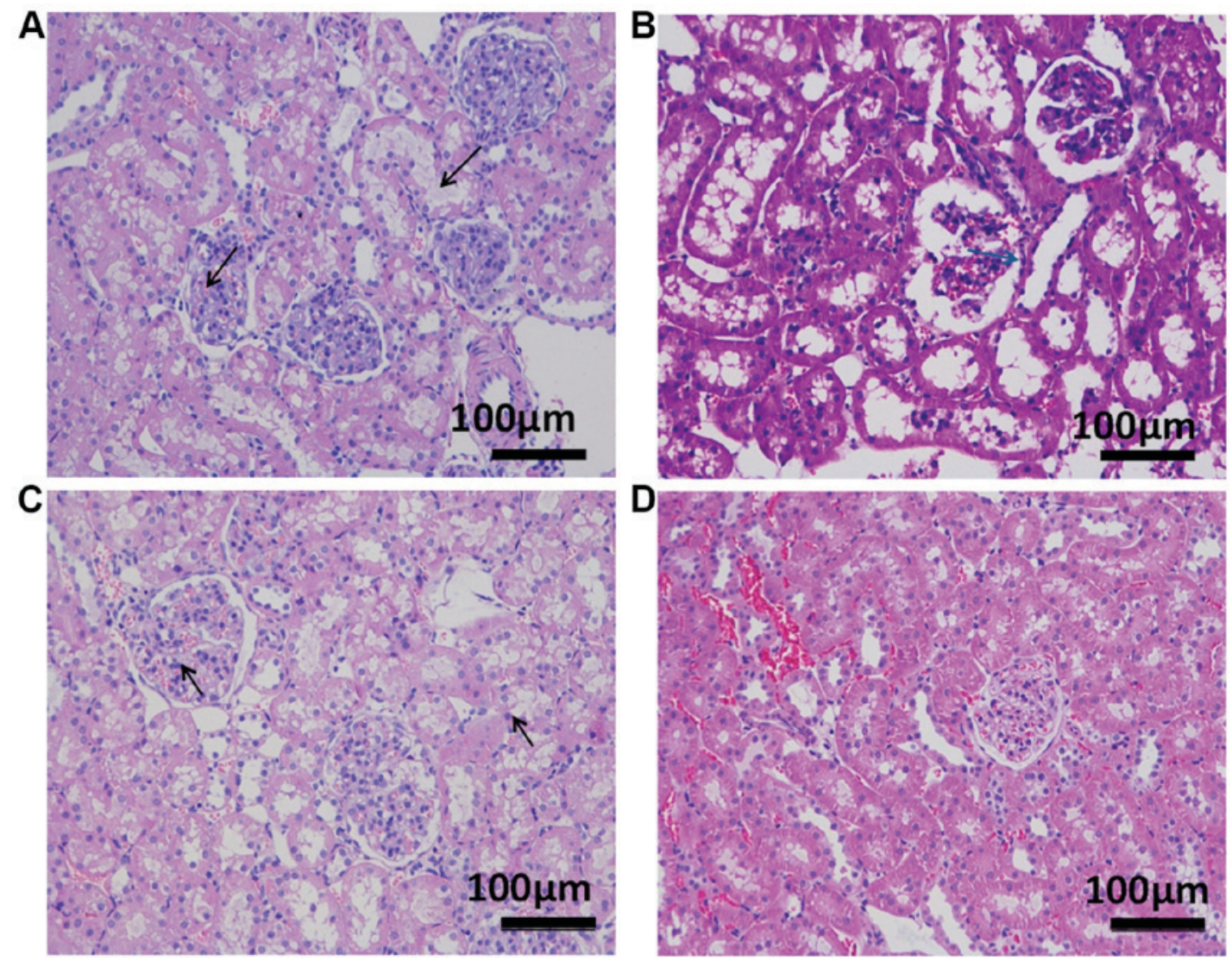

Figure 3. Light microscopy image of hematoxylin \& eosin staining of kidney tissue of different hypoxia groups at magnification, x200. (A) Intermittent hypoxia group. (B) Continuous hypoxia group. (C) Intermittent hypoxia with hypercapnia group. (D) Control group. Mild vacuole degeneration was identified in the renal tubular epithelial cells as indicated by the black arrows. IHH, intermittent hypoxia with hypercapnia; $\mathrm{IH}$, intermittent hypoxia; $\mathrm{CH}$, constant hypoxia; HE, hematoxylin and eosin.
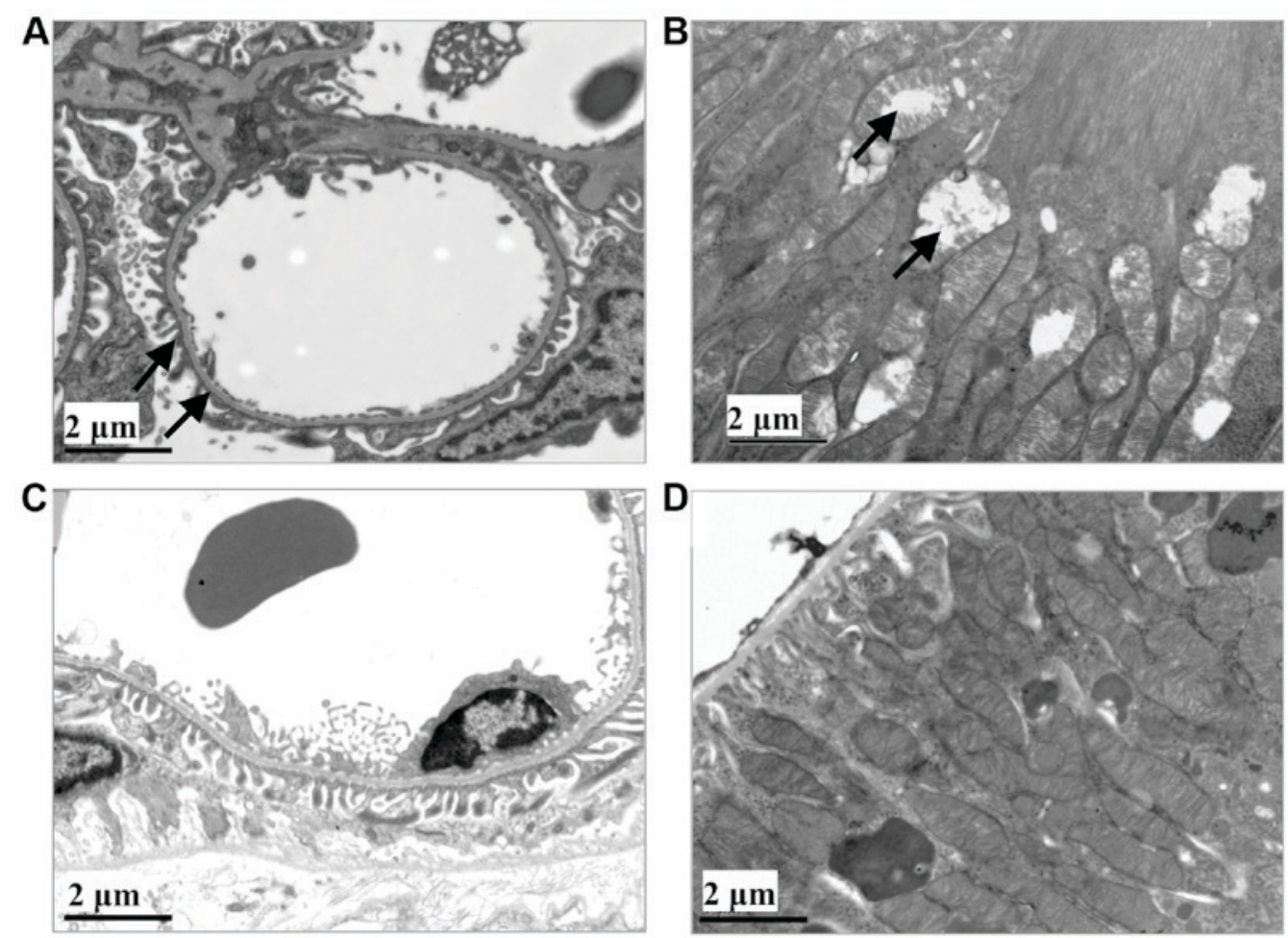

Figure 4. Transmission electron microscope of rat kidney tissue at magnification, x15,000. Hypoxia group demonstrating (A) glomerulus and (B) renal tubule areas. Control group demonstrating (C) glomerulus and (D) renal tubule areas. Foot process fusion was visualized in the glomerulus of (A) compared with (C) as indicated by black arrows. Swelling of mitochondria and vacuoles was identified in the tubules in (B) and compared with (C) as indicated by black arrows. 

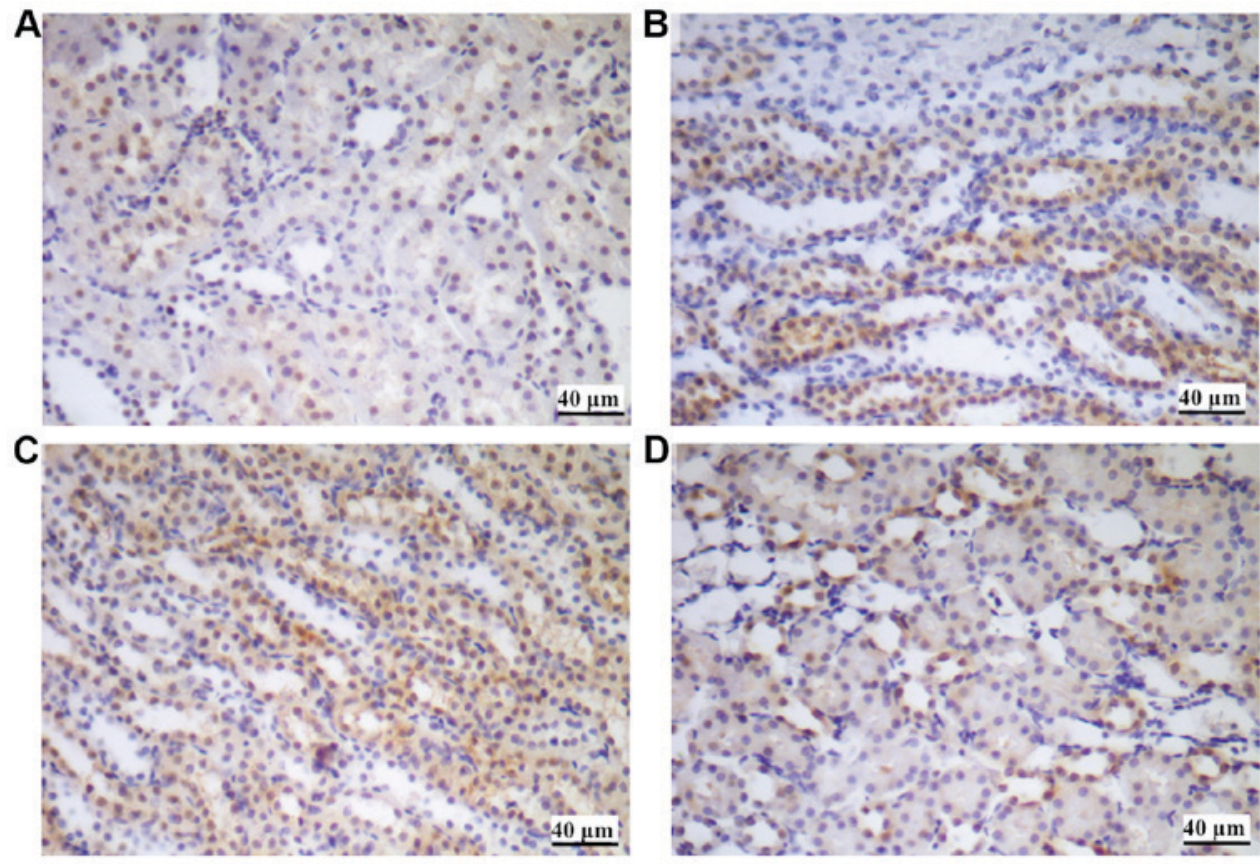

Figure 5. HMGB1 immunohistochemical staining of renal tissues. (A) Control. (B) CH group. (C) IH group. (D) IHH group. The expression of HMGB1 was identified primarily in the nucleus of the renal tubular epithelial cells, as demonstrated in (A). The expression and translocation of HMGB1 was increased in the (B) $\mathrm{CH}$ group, (C) IH group and (D) IHH group compared with the control. IHH, intermittent hypoxia with hypercapnia; IH, intermittent hypoxia; $\mathrm{CH}$, continuous hypoxia; HMGB1, high mobility group box 1 protein.

suggesting the upregulation of nuclear translocation (from nucleus to cytoplasm) during stimulation by hypoxia (Fig. 5).

mRNA expression of HMGB1 signaling detected by RT-qPCR. Hypoxia stimulated the expression of HMGB1, TNF- $\alpha$, PPAR and RAGE in the rat renal tissues, and decreased the expression of SIRT1 (Fig. 6; Table II). Compared with the control group $(0.61 \pm 0.24)$, the expression of HMGB1 mRNA in the $\mathrm{CH}$ $(1.14 \pm 0.35)$, IH $(1.30 \pm 0.40)$ and IHH $(1.10 \pm 0.42)$ groups was significantly upregulated $(\mathrm{P}<0.05)$. In addition, compared with the control group $(1.15 \pm 0.13)$, IH treatment $(2.47+0.85)$ caused a significant increase in RAGE mRNA expression $(\mathrm{P}<0.05)$. $\mathrm{CH}(1.71+0.54)$ and $\mathrm{IHH}(1.30+0.47)$ treatments also resulted an increase in RAGE mRNA expression, but the differences were not statistically significant $(\mathrm{P}>0.05)$. The expression of PPAR and TNF- $\alpha$ mRNA in the $\mathrm{CH}$, IH and IHH groups was significantly increased $(\mathrm{P}<0.05)$ compared with the control group. The IL-6 mRNA levels in the $\mathrm{CH}$, IH and IHH groups were also increased compared with the control group, but the differences were not statistically significant ( $\mathrm{P}>0.05$; Table II). No significant differences in the expression of $N F-\kappa B$ and TLR4 mRNA were observed in the hypoxia groups compared with the control group $(\mathrm{P}>0.05)$. Levels of SIRT1 mRNA in the IHH group $(0.73+0.27)$ were significantly decreased compared with the control group $(1.0 \pm 0.07 ; \mathrm{P}<0.05)$. No significant differences in SIRT1 mRNA expression in the CH $(0.88 \pm 0.21)$ and $\mathrm{IH}(0.94 \pm 0.29)$ groups compared with the control group $(\mathrm{P}>0.05)$ were observed.

Expression of IL-6, TNF- $\alpha$, soluble (s)TLR2, sTLR4 and SPPAR in the peripheral blood detected by ELISA. Hypoxia increased the expression of IL-6, TNF- $\alpha$, soluble TLR4, and decreased the expression of soluble TLR2 and PPAR (Fig. 7).
In the IHH group, the expression of the sTLR2 $(16.35 \pm 15.21$ vs. $33.84 \pm 14.28)$ and sPPAR (11.00 \pm 6.99 vs. $23.00 \pm 9.30)$ in the peripheral blood was significantly decreased compared with the control group $(\mathrm{P}<0.05)$. In addition, compared with the control group, no significant difference in the expression of sTLR2 and sPPAR in $\mathrm{CH}$ and $\mathrm{IH}$ were observed $(\mathrm{P}>0.05)$. It was also demonstrated that hypoxia increased the levels of TNF- $\alpha$, IL-6 and sTLR4 expression in the peripheral blood. The expression of TNF- $\alpha$ in the $\mathrm{CH}(3.48 \pm 0.69), \mathrm{IH}$ $(3.54 \pm 1.40)$ and $\mathrm{IHH}(3.52 \pm 1.39)$ groups was significantly upregulated compared with the controls $(2.29 \pm 0.78 ; \mathrm{P}<0.05)$.

The expression of IL- 6 in the $\mathrm{CH}(547.13 \pm 71.95)$ and $\mathrm{IH}$ (459.54 \pm 65.13$)$ groups was significantly upregulated compared with the controls $(267.11 \pm 26.65 ; \mathrm{P}<0.05)$. However, there was no significant difference in IL-6 expression between the IHH and control groups (242.08 \pm 21.01 vs. $267.11 \pm 26.65 ; \mathrm{P}>0.05)$.

The expression of sTLR4 was significantly increased in the IHH group compared with the controls $(4.39 \pm 2.28$ vs. $2.12 \pm 0.88 ; \mathrm{P}<0.05)$. In addition, compared to the controls, there was an increase in sTLR4 expression in the $\mathrm{CH}$ and $\mathrm{IH}$ groups, but the difference was not significant $(\mathrm{P}>0.05)$.

\section{Discussion}

The present study demonstrated that hypoxia stimulation may cause early renal injury at the subcellular level and increase the expression and translocation of HMGB1. Hypoxia also upregulated the mRNA expression of factors of the HMGB1RAGE-TNF- $\alpha$ pathway in kidney tissues, and increased the expression of sTLR4, TNF- $\alpha$ and IL-6 in the peripheral blood. This suggested that the HMGB1-RAGE/TLR-TNF- $\alpha$ signaling pathway may contribute to the molecular mechanisms of early renal injury induced by hypoxia. This pathway may also be a 
Table II. Expression levels of HMGB1, IL-6, PPAR, RAGE, NF- $\kappa B$, TLR4, SIRT1 and TNF- $\alpha$ mRNA in kidney tissues.

Relative expression

\begin{tabular}{lcccc}
\cline { 2 - 5 } Gene & $\mathrm{C}$ & $\mathrm{CH}$ & $\mathrm{IH}$ & $\mathrm{IHH}$ \\
\hline HMGB1 & $0.61 \pm 0.24$ & $1.14 \pm 0.35^{\mathrm{a}}$ & $1.30 \pm 0.40^{\mathrm{a}}$ & $1.10 \pm 0.42^{\mathrm{a}}$ \\
IL-6 & $0.99 \pm 0.59$ & $1.39 \pm 1.16$ & $1.53 \pm 0.44$ & $1.17 \pm 0.93$ \\
PPAR & $1.04 \pm 0.07$ & $1.69 \pm 0.42^{\mathrm{a}}$ & $2.66 \pm 0.59^{\mathrm{a}}$ & $1.73 \pm 0.34^{\mathrm{a}}$ \\
RAGE & $1.15 \pm 0.13$ & $1.71 \pm 0.54$ & $2.47 \pm 0.85^{\mathrm{a}}$ & $1.30 \pm 0.47$ \\
NF-kB & $3.27 \pm 0.77$ & $3.54 \pm 1.54$ & $3.14 \pm 1.25$ & $2.94 \pm 1.15$ \\
TLR4 & $1.13 \pm 0.59$ & $1.23 \pm 0.52$ & $0.81 \pm 0.25$ & $1.06 \pm 0.62$ \\
SIRT1 & $1.03 \pm 0.07$ & $0.88 \pm 0.21$ & $0.94 \pm 0.29$ & $0.73 \pm 0.27^{\mathrm{b}}$ \\
TNF- $\alpha$ & $0.92 \pm 0.52$ & $1.75 \pm 1.27^{\mathrm{a}}$ & $3.34 \pm 2.56^{\mathrm{a}}$ & $2.06 \pm 0.86^{\mathrm{a}}$
\end{tabular}

${ }^{a} \mathrm{P}<0.05$ vs. $\mathrm{C}$; ${ }^{b} \mathrm{P}<0.05$ vs. C. C, control; $\mathrm{CH}$, continuous hypoxia; $\mathrm{IH}$, intermittent hypoxia; $\mathrm{IHH}$, intermittent hypoxia with hypercapnia; HMGB1, high mobility group box 1 protein; IL, interleukin; PPAR, peroxisome proliferator-activated receptor; RAGE, receptor for advanced glycosylation end products; NF, nuclear factor; TLR4, toll-like receptor 4; SIRT1, NAD-dependent deacetylase sirtuin-1; TNF, tumor necrosis factor.

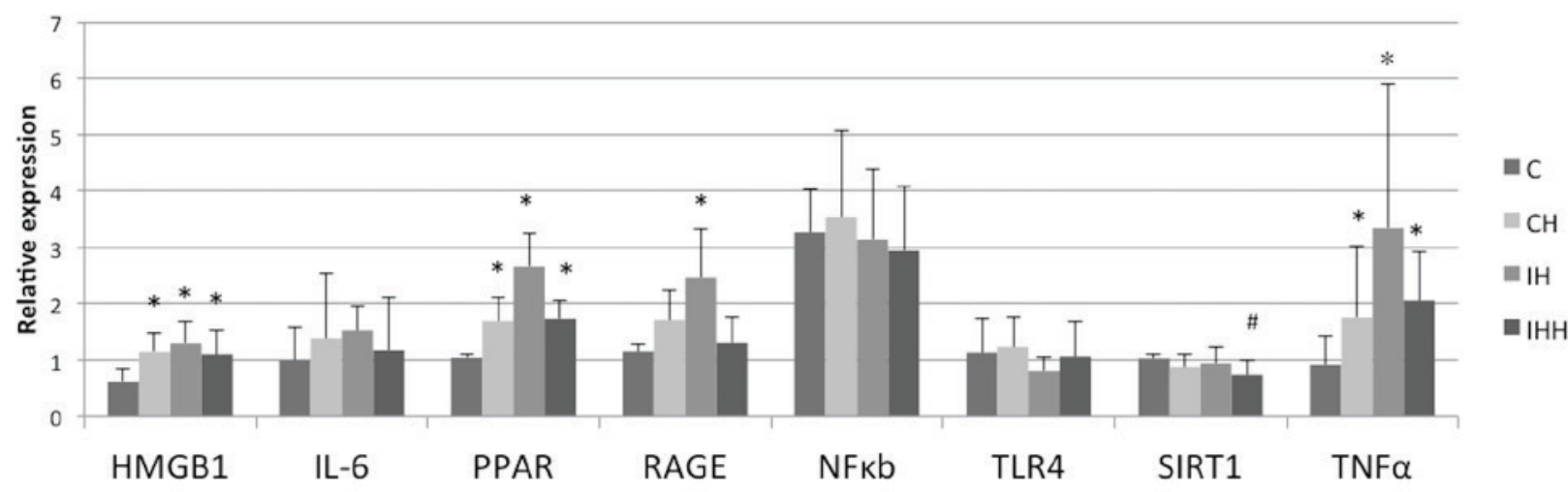

Figure 6. Expression of HMGB1, IL-6, PPAR, RAGE, TNF- $\alpha$, SIRT1, TLR4 and NF-kB mRNA in kidney tissues. CH, IH and IHH treatment increased the mRNA expression of HMGB1, TNF- $\alpha$ and PPAR in kidney tissues. IH increased the expression of RAGE mRNA. The expression of IL-6 mRNA exhibited an upward trend in all hypoxia groups, but the change was not statistically significant. IHH downregulated the expression of SIRT1 mRNA. There was no significant difference in the expression of NF- $\mathrm{KB}$ and TLR4 mRNA between the hypoxia groups and controls. " $\mathrm{P}<0.05$ vs. control. $\mathrm{CH}, \mathrm{Continuous} \mathrm{hypoxia;} \mathrm{IH,}$ intermittent hypoxia; IHH, intermittent hypoxia with hypercapnia; HMGB1, high mobility group box 1 protein; RAGE, receptor for advanced glycosylation end products; TLR, toll-like receptor; TNF- $\alpha$, tumor necrosis factor $\alpha$; IL, interleukin; NF-KB, nuclear factor kappa-light-chain-enhancer of active B cells; PPAR, peroxisome proliferator-activated receptor; SIRT1, NAD-dependent protein deacetylase sirtuin-1.

marker for OSA-associated early renal injury and serve as a future drug intervention target.

Previously, increasing evidence has revealed a close association between OSA and CKD. Intermittent hypoxia that occurs in OSA may cause renal damage, which is an important risk factor for CKD $(3,4)$. However, at present, the molecular mechanisms of kidney injury induced by intermittent hypoxia are not fully understood. If the core molecular mechanism was identified, and its central players used as intervention targets, it may serve a vital role in the prevention and control of OSA-associated CKD. The primary mechanism of OSA-induced disease complications is considered to be immune inflammation (5). Hypoxia and oxidative stress in OSA may cause direct cell damage, and the damaged cells and extracellular matrix may release the decomposition products of proteins and nucleic acid that serve as 'danger signals', known as DAMPs. HMGB1, as the most important representative DAMP, has attracted much attention (7). It is a highly conserved nuclear protein that is abundant in mammalian cells, which is transferred from the necrotic nucleus to the cytoplasm and then released to the extracellular matrix. HMGB1 may promote inflammation by combining with RAGE and TLR4 and TLR2 $(10,11)$. Inflammatory injury causes additional DAMPs to be released, stimulating further inflammation.

In the present study, $\mathrm{CH}, \mathrm{IH}$ and $\mathrm{IHH}$ rat models were established. The effects of hypoxia stimulation on the renal histopathological and ultrastructural changes, and the expression of HMGB1 and its subsequent inflammatory pathway mediators in the kidney tissues and peripheral bloods of rats, were investigated.

The results of the present study suggested that there was no severe histopathological injury, as indicated by HE staining of the hypoxia groups; however, a certain degree of renal tubular epithelial cell vacuolation was observed. By contrast, ultrastructural changes, detected by electron microscopy, 

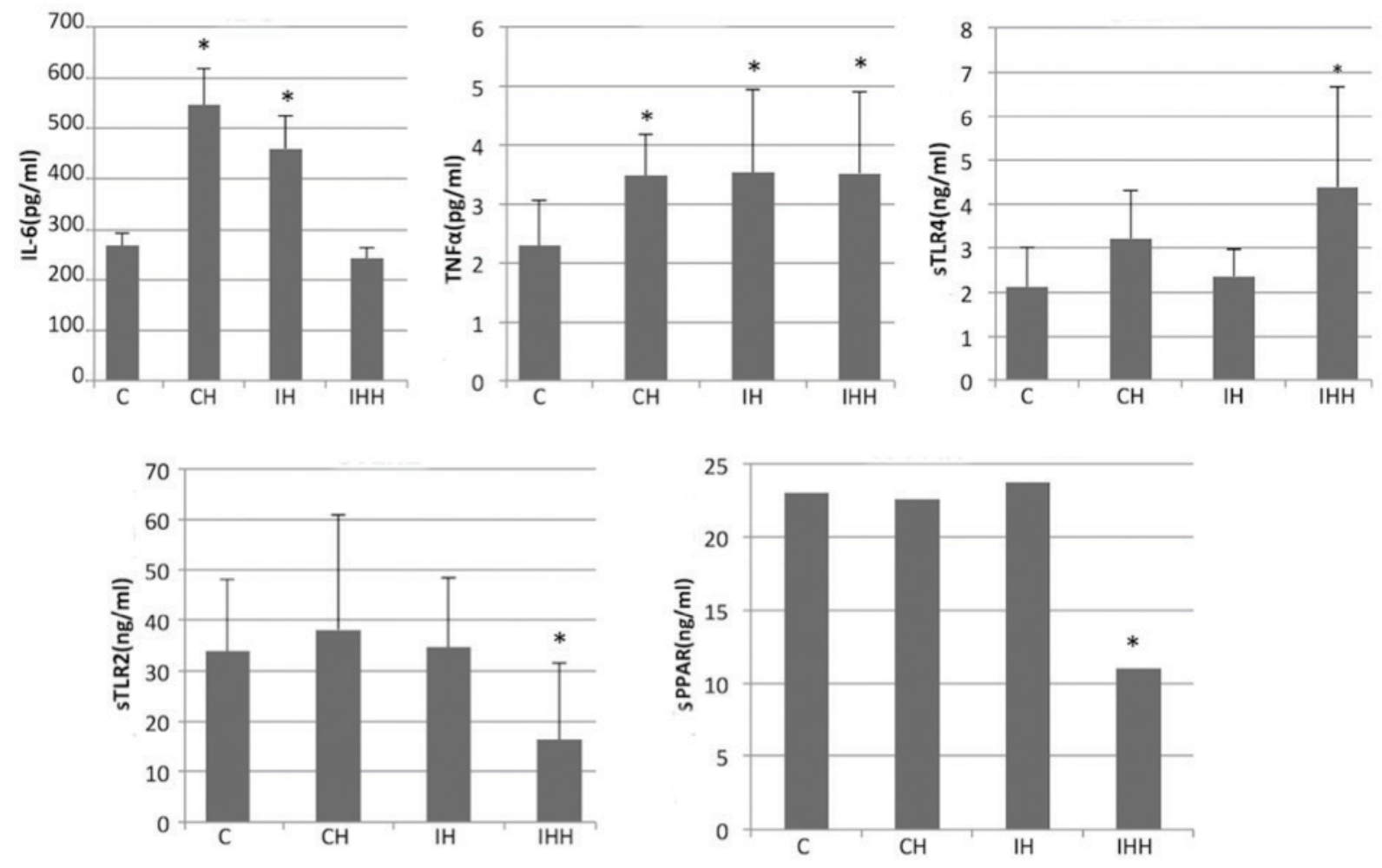

Figure 7. Expression of IL-6, sPPAR, sTLR2, sTLR4 and TNF- $\alpha$ in the peripheral blood of rats. CH, IH and IHH increased the expression of TNF- $\alpha$. CH and IH treatment increased the expression of IL-6 and IHH increased the expression of sTLR4 significantly. IHH treatment decreased the expression of sTLR2 and sPPAR- $\gamma$ protein. "P<0.05 vs. controls. $\mathrm{CH}$, continuous hypoxia; IH, intermittent hypoxia; IHH, intermittent hypoxia with hypercapnia; s, soluble; TLR, toll-like receptor; TNF- $\alpha$, tumor necrosis factor $\alpha$; IL, interleukin; NF, nuclear factor kappa-light-chain-enhancer of active B cells; PPAR, peroxisome proliferator-activated receptor; SIRT1, NAD-dependent deacetylase sirtuin-1.

were more significant in the hypoxia groups including foot process fusion, increased secondary lysosomes and swelling and degeneration of mitochondria. The subcellular structural changes of the kidney tissue suggested early renal injury due to hypoxia.

Then, the expression of HMGB1 and its subsequent signaling pathway mediators were detected by IHC, qPCR and ELISA, in order to explore the underlying molecular mechanisms of early renal injury. IHC staining demonstrated that the overall expression and the expression in the cytoplasm of the HMGB1 protein was increased in the hypoxia groups compared with the controls. This suggested that hypoxia may upregulate the expression of HMGB1, and may also increase its the nuclear translocation (from nucleus to cytoplasm); this is where the HMGB1 protein is then acetylated to its active form in the cytoplasm (19). An increased expression of HMGB1 in the cytoplasm suggested an increase in HMGB1 activity.

The results of the qPCR indicated that hypoxia stimulation increased the expression of HMGB1, RAGE and TNF- $\alpha$ mRNA $(\mathrm{P}<0.05)$. RAGE was the earliest identified HMGB1 receptor, belonging to the immunoglobulin superfamily transmembrane receptor, and is widely expressed in a variety of immune and endothelial cells, and on the surface of other cells $(2,13)$. In combination with the respective ligands, these receptors may induce intracellular signal transduction via the Ras-mitogen-activated protein kinase pathway and $\mathrm{NF}-\kappa \mathrm{B}$ translocation and mediate an inflammatory response. The increased expression of HMGB1-RAGE signaling factors in kidney tissues suggested that hypoxia may activate this pathway, which may serve a key role in early renal inflammatory injury induced by hypoxia.

It has been established that sleep apnea may lead to renal function damage, which is closely associated with proteinuria and CKD (20,21). If the HMGB1-RAGE-TNF- $\alpha$ pathway serves an important role in renal injury due to sleep apnea, the pathway may be a key target for intervention. A previous clinical study demonstrated that the HMGB1 level was increased in patients with OSA compared with the controls, and that effective CPAP treatment downregulated the HMGB1 level (22). An additional study also indicated that dexmedetomidine may downregulate the expression of the HMGB1-TLR-NF- $\kappa \mathrm{B}$ signaling pathway and decrease ischemia-reperfusion injury (23). Glycyrrhizin decreased ischemia-reperfusion injury in a mouse brain by decreasing the expression of HMGB1 and the subsequent inflammatory factors (24).

The present study also suggested that hypoxia stimulation decreased the expression of SIRT1 mRNA and increased that of PPAR mRNA in kidney tissues $(\mathrm{P}<0.05)$. SIRT1 and PPAR are two inhibitors of this pathway. SIRT1 protein is a NAD+ dependent protein deacetylase and regulates gene transcription by deacetylation $(15,25)$. It is a key aging-associated gene and is an important anti-inflammatory, antioxidant and inflammatory repair factor. The expression of SIRT1 in renal tissue was decreased in the IHH group in the present study, suggesting that intermittent hypoxia with high $\mathrm{CO}_{2}$ may downregulate SIRT1 expression and thereby weaken the 
effect of deacetylation, which may result in increased acetylation and activation of HMGB1 and increased inflammatory injury. This may be a mechanism of renal inflammation injury induced by hypoxia. PPAR, as a nuclear receptor transcription factor superfamily, has attracted increasing attention for its role in regulating target gene expression (17). According to its receptor structure, PPAR may be divided into three subtypes: $\alpha, \beta$ and $\gamma$. PPAR $\gamma$ is abundantly distributed in adipose tissue, and also expressed in vascular endothelial cells and mononuclear macrophages. In the present study, hypoxia stimulation caused an increase of PPAR mRNA expression in renal tissues, which may be a compensatory and protective mechanism during hypoxia against inflammation. The increased expression of PPAR $\gamma$ may inhibit the transcription of HMGB1 and other inflammatory factors by inhibiting signaling pathways, including the $\mathrm{NF}-\kappa \mathrm{B}$ pathway. Previous studies have indicated that PPAR $\gamma$ agonists serve a role in protecting the kidneys from injury $(26,27)$.

The results of the ELISAs revealed that hypoxia stimulation increased the expression of sTLR 4 , TNF- $\alpha$ and IL- 6 in the peripheral blood, and decreased the expression of sTLR2 and PPAR $\gamma$. The increase in STLR4 expression during hypoxia suggested an activation of TLR4 associated innate immunity, by which HMGB1 exerted its inflammatory effects. Previous studies have demonstrated that HMGB1-TLR4 signaling may induce IL-17A secretion and lead to brain ischemia/reperfusion injury $(24,28)$. A previous study indicated that TLR4 (-/-) mice were protected against ischemia/reperfusion injury of the kidney (29). In the present study, TLR4 expression was detected by RT-qPCR and ELISA. It was identified that there was no significant increase in the levels of TLR4 mRNA, while the levels of sTLR4 protein increased significantly during hypoxia. The results may be due to the relatively short hypoxia time ( 2 weeks) and the difference in TLR4 expression between kidney tissues and peripheral blood requires additional investigation.

The present study also demonstrated that hypoxia decreased the expression of STLR2 protein in the peripheral blood. In a number of diseases, sTLRs are considered to be natural regulators of TLRs, which may interact with cell-surface TLR2 and maintain their levels within a reasonable range to avoid excessive inflammation injury $(30,31)$. sTLR 2 released by stimulated immune cells constitutes an important first-line negative regulatory mechanism $(31,32)$. In the present study, the expression of sTLR2 protein in peripheral blood was decreased. This was similar to unpublished results from our previous study, which revealed that the expression of sTLR2 in the peripheral blood was significantly decreased compared with that prior to sleep in 35 patients with OSA. This suggests that sTLR2 may be a negative regulator in the inflammatory response.

Different hypoxia models were used in the present study, including $\mathrm{CH}$, IH and $\mathrm{IHH}$. The results demonstrated that the effects on the HMGB1 signal pathway were not identical between these different models. For example, RAGE mRNA expression was increased only in the IH group, but not in the $\mathrm{CH}$ and IHH groups. The decrease of SIRT1 mRNA expression was only detected in IHH group. For example, in the IHH group with high $\mathrm{CO}_{2}, \mathrm{CO}_{2}$ serves its unique role: The effects of
$\mathrm{CO}_{2}$ and $\mathrm{O}_{2}$ stimulation on the expression of relevant proteins are not identical. In some circumstance, $\mathrm{CO}_{2}$ may also be a protective factor $(33,34)$. For example, kidney cell apoptosis was reduced in the hypercapnic acidosis group compared with the normocapnia group in acute lung injury rat models. It was suggested that hypercapnia exerted a protect effect and reduced kidney cell apoptosis (33). In addition, hypercapnia has been demonstrated to significantly decreased LPS-induced $\mathrm{NF}-\kappa \mathrm{B}$ activation by suppression of I $\mathrm{B}-\alpha$ degradation, which in turn attenuate neutrophil recruitment and lung injury (35). Additional studies are required to clarify the specific differences in the effect of $\mathrm{CO}_{2}$ and $\mathrm{O}_{2}$.

In summary, the present study explored the effect of hypoxia on the expression of HMGB1 and its subsequent inflammatory pathway. Hypoxia stimulation caused renal injury at the subcellular level, and an increase of HMrutGB1 expression and translocation. In addition, hypoxia also upregulated the expression of the HMGB1-RAGE/TLR-TNF pathway, suggesting that this pathway may be a key molecular mechanism in OSA-associated renal injury and a target for future drug development.

Limitations of the present study included: Only 2 weeks of hypoxia were applied to explore the mechanism of early renal injury due to hypoxia. Long-term chronic hypoxia should be studied to explore the effect of chronic hypoxia on kidney tissues. Furthermore, $\mathrm{CO}_{2}$ serves a unique role in OSA-associated kidney injury. A simple intermittent high $\mathrm{CO}_{2}$ group should be established to explore the mechanism of $\mathrm{CO}_{2}$ in this process. In addition, the present study only investigated the expression levels of the HMGB1 signaling pathway, and an in vitro intervention study should be performed to explore additional molecular pathways.

\section{Acknowledgements}

The authors would like to thank Professor Jue Zhang from the Academy for Advanced Interdisciplinary Studies, Peking University (Beijing, China) for his help in developing the hypoxia chamber. The authors would further like to thank Professor Dingfang Bu of the Central Lab of Peking University First Hospital (Beijing, China) for his support regarding qPCR.

\section{Funding}

The current study was supported by the National Natural Science Foundation of China (grant no. 81341005).

\section{Availability of data and materials}

The datasets used and/or analyzed during the present study are available from the corresponding author on reasonable request.

\section{Authors' contributions}

$\mathrm{CZ}$ and HD established the hypoxia model and performed HE staining. CZ and FWC performed qPCR analysis. $\mathrm{CZ}$ and YXW performed IHC staining. JM and GFW conceived and designed the study and revised the manuscript. All authors read and approved the final manuscript. 


\section{Ethics approval and consent to participate}

The present study was approved by the Animal Ethics Committee of Peking University First Hospital (Beijing, China).

\section{Patient consent for publication}

Not applicable.

\section{Competing interests}

The authors declare that they have no competing interests.

\section{References}

1. Vijayan VK: Morbidities associated with obstructive sleep apnea. Expert Rev Respir Med 6: 557-566, 2012

2. Wu X, Gu W, Lu H, Liu C, Yu B, Xu H, Tang Y, Li S, Zhou J and Shao C: Soluble receptor for advanced glycation end product ameliorates chronic intermittent hypoxia induced renal injury, inflammation, and apoptosis via P38/JNK Signaling Pathways. Oxid Med Cell Longev 2016: 1015390, 2016.

3. Adeseun GA and Rosas SE: The impact of obstructive sleep apnea on chronic kidney disease. Curr Hypertens Rep 12: 378-383, 2010.

4. Adams RJ, Appleton SL, Vakulin A, Hanly PJ, McDonald SP Martin SA, Lang CJ, Taylor AW, McEvoy RD, Antic NA, et al: Chronic kidney disease and sleep apnea association of kidney disease with obstructive sleep apnea in a population study of men. Sleep 40: Jan 1, 2017 doi: 10.1093/sleep/zsw015.

5. Wei Q, Bian Y, Yu F, Zhang Q, Zhang G, Li Y, Song S, Ren X and Tong J: Chronic intermittent hypoxia induces cardiac inflammation and dysfunction in a rat obstructive sleep apnea model. J Biomed Res 30: 490-495, 2016.

6. Zhu S, Li W, Ward MF, Sama AE and Wang H: High mobility group box 1 protein as a potential drug target for infection- and injury-elicited inflammation. Inflamm Allergy Drug Targets 9: 60-72, 2010.

7. Piccinini $\mathrm{AM}$ and Midwood KS: DAMPening inflammation by modulating TLR signalling. Mediators Inflamm 2010: pii: $672395,2010$.

8. Kent BD, Ryan S and McNicholas WT: Obstructive sleep apnea and inflammation: Relationship to cardiovascular co-morbidity. Respir Physiol Neurobiol 178: 475-481, 2011.

9. Andrassy M, Volz HC, Igwe JC, Funke B, Eichberger SN, Kaya Z, Buss S, Autschbach F, Pleger ST, Lukic IK, et al: High-mobility group box-1 in ischemia-reperfusion injury of the heart. Circulation 117: 3216-3226, 2008.

10. Hori O, Brett J, Slattery T, Cao R, Zhang J, Chen JX, Nagashima M, Lundh ER, Vijay S and Nitecki D: The receptor for advanced glycation end products (RAGE) is a cellular binding site for amphoterin. Mediation of neurite outgrowth and co-expression of rage and amphoterin in the developing nervous system. J Biol Chem 270: 25752-25761, 1995.

11. Tadie JM, Bae HB, Jiang S, Park DW, Bell CP, Yang H, Pittet JF, Tracey K, Thannickal VJ, Abraham E and Zmijewski JW: HMGB1 promotes neutrophil extracellular trap formation through interactions with Toll-like receptor 4. Am J Physiol Lung Cell Mol Physiol 304: L342-L349, 2013.

12. Chavakis T, Bierhaus A and Nawroth PP: RAGE (receptor for advanced glycation end products): A central player in the inflammatory response. Microbes Infect 6: 1219-1225, 2004

13. Yu SL, Wong CK, Szeto CC, Li EK, Cai Z and Tam LS: Members of the receptor for advanced glycation end products axis as potential therapeutic targets in patients with lupus nephritis. Lupus 24: 675-686, 2015.

14. Schnare M, Barton GM, Holt AC, Takeda K, Akira S and Medzhitov R: Toll-like receptors control activation of adaptive immune responses. Nat Immunol 2: 947-950, 2001.

15. Kozako T, Aikawa A, Shoji T, Fujimoto T, Yoshimitsu M, Shirasawa S, Tanaka H, Honda S, Shimeno H, Arima N and Soeda S: High expression of the longevity gene product SIRT1 and apoptosis induction by sirtinol in adult T-cell leukemia cells. Int J Cancer 131: 2044-2055, 2012.

16. Michan S and Sinclair D: Sirtuins in mammals: Insights into their biological function. Biochem J 404: 1-13, 2007.
17. Villapol S: Roles of peroxisome proliferator-activated receptor gamma on brain and peripheral inflammation. Cell Mol Neurobiol 38: 121-132, 2018.

18. Livak KJ and Schmittgen TD: Analysis of relative gene expression data using real-time quantitative PCR and the 2(-Delta Delta C(T)) method. Methods 25: 402-408, 2001.

19. Klune JR, Dhupar R, Cardinal J, Billiar TR and Tsung A: HMGB1: Endogenous danger signaling. Mol Med 14: 476-484, 2008.

20. Ahmed SB, Ronksley PE, Hemmelgarn BR, Tsai WH, Manns BJ, Tonelli M, Klarenbach SW, Chin R, Clement FM and Hanly PJ: Nocturnal hypoxia and loss of kidney function. PLoS One 6: e19029, 2011.

21. Hanly PJ and Ahmed SB: Sleep apnea and the kidney: Is sleep apnea a risk factor for chronic kidney disease? Chest 146: 1114-1122, 2014

22. Wu KM, Lin CC, Chiu CH and Liaw SF: Effect of treatment by nasal continuous positive airway pressure on serum high mobility group box-1 protein in obstructive sleep apnea. Chest 137: 303-309, 2010.

23. Zhang JJ, Peng K, Zhang J, Meng XW and Ji FH: Dexmedetomidine preconditioning may attenuate myocardial ischemia/reperfusion injury by down-regulating the HMGB1-TLR4-MyD88-NF-KB signaling pathway. PLoS One 12: e0172006, 2017.

24. Zhang J, Wu Y, Weng Z, Zhou T, Feng T and Lin Y: Glycyrrhizin protects brain against ischemia-reperfusion injury in mice through HMGB1-TLR4-IL-17A signaling pathway. Brain Res 1582: 176-186, 2014.

25. Lee IC, Ho XY, George SE, Goh CW, Sundaram JR, Pang KKL, Luo W, Yusoff P, Sze NSK and Shenolikar S: Oxidative stress promotes SIRT1 recruitment to the GADD34/PP1 $\alpha$ complex to activate its deacetylase function. Cell Death Differ 25: 255-267, 2017.

26. Chen DZ, Chen LQ, Lin MX, Gong YQ, Ying BY and Wei DZ: Esculentoside A inhibits LPS-induced acute kidney injury by activating PPAR- $\gamma$. Microb Pathog 110: 208-213, 2017.

27. Wu SH, Wang MJ, Lü J and Chen XQ: Signal transduction involved in lipoxin A4-induced protection of tubular epithelial cells against hypoxia/reoxygenation injury. Mol Med Rep 15: 1682-1692, 2017.

28. Zhu H, Li J, Wang S, Liu K, Wang L and Huang L: Hmgb1-TLR4-IL-23-IL-17A axis promote ischemia-reperfusion injury in a cardiac transplantation model. Transplantation 95: 1448-1454, 2013.

29. Wu H, Chen G, Wyburn KR, Yin J, Bertolino P, Eris JM, Alexander SI, Sharland AF and Chadban SJ: TLR4 activation mediates kidney ischemia/reperfusion injury. J Clin Invest 117: 2847-2859, 2007.

30. Dulay AT, Buhimschi CS, Zhao G, Oliver EA, Mbele A, Jing S and Buhimschi IA: Soluble TLR2 is present in human amniotic fluid and modulates the intraamniotic inflammatory response to infection. J Immunol 182: 7244-7253, 2009.

31. Henrick BM, Yao XD, Taha AY, German JB and Rosenthal KL: Insights into soluble Toll-Like receptor 2 as a downregulator of virally induced inflammation. Front Immunol 7: 291, 2016.

32. Raby AC, Le Bouder E, Colmont C, Davies J, Richards P, Coles B, George CH, Jones SA, Brennan P, Topley N and Labéta MO: SolubleTLR 2 reduces inflammation without compromising bacterial clearance by disrupting TLR2 triggering. J Immunol 183: 506-517, 2009.

33. Nardelli LM, Rzezinski A, Silva JD, Maron-Gutierrez T, Ornellas DS, Henriques I, Capelozzi VL, Teodoro W, Morales MM, Silva PL, et al: Effects of acute hypercapnia with and without acidosis on lung inflammation and apoptosis in experimental acute lung injury. Respir Physiol Neurobiol 205: 1-6, 2015.

34. Ni Chonghaile M, Higgins BD, Costello JF and Laffey JG: Hypercapnic acidosis attenuates severe acute bacterial pneumonia-induced lung injury by a neutrophil-independent mechanism. Crit Care Med 36: 3135-3144, 2008.

35. Takeshita K, Suzuki Y, Nishio K, Takeuchi O, Toda K, Kudo H, Miyao N, Ishii M, Sato N, Naoki K, et al: Hypercapnic acidosis attenuates endotoxin-induced nuclear factor-[kappa]B activation. Am J Respir Cell Mol Biol 29: 124-132, 2003.

This work is licensed under a Creative Commons Attribution-NonCommercial-NoDerivatives 4.0 International (CC BY-NC-ND 4.0) License. 